Trabajos y Comunicaciones, 2da. Época, No 46, e049, octubre 2017. ISSN 2346-8971

Universidad Nacional de La Plata.

Facultad de Humanidades y Ciencias de la Educación.

Departamento de Historia

\title{
Scarzanella, Eugenia. Abril. Un editor italiano en Buenos Aires, de Perón a Videla. Buenos Aires: Fondo de Cultura Económica, 2016, 278 páginas
}

\author{
Bontempo María Paula * \\ * Instituto Interdisciplinario de Estudios de Género-Facultad de Filosofía y Letras- \\ Universidad de Buenos Aires /Universidad Nacional Arturo Jauretche, Argentina | \\ paubontempo@yahoo.com.ar
}

Desde hace algunas décadas, han proliferado libros, artículos y tesis de maestría y de doctorado que han puesto el foco en la prensa escrita - local, cultural, partidaria, sindical, religiosa o comercial- para comprender procesos históricos como la formación de una cultura de masas, las representaciones de género, la afirmación de identidades de clase, las construcciones de públicos y audiencias y la radicalización política, entre otras preocupaciones. Sin embargo, no son muchas las investigaciones que abordan un grupo editorial comercial en su conjunto y lo estudian en un plazo mediano o largo. La carencia de este tipo de trabajos responde, por una parte, a la dificultad metodológica que suscita dar cuenta de un conjunto que publicaciones que se editan simultáneamente -qué pueden convertirse en un éxito o un fracaso- y que suelen estar dirigidas a públicos diversos y en ocasiones con orientaciones temáticas, estilísticas e ideológicas diferentes. Por otra parte, la ausencia de trabajos sobre las empresas editoras en sus distintas dimensiones proviene de la dificultad del acceso a las fuentes que proporcionen información acerca de los vaivenes económicos del grupo, de las decisiones editoriales respecto a los temas publicables, de la vida en las redacciones, de las opciones políticas respecto a los gobiernos de turno.

Estos desafíos fueron asumidos por Eugenia Scarzanella en su libro "Abril. Un editor italiano en Buenos Aires, de Perón a Videla” editado en Argentina por el Fondo de Cultura Económica en 2016, como traducción de una obra publicada originalmente en italiano en el año 2013. La autora, especializada en historia argentina, es Doctora en Ciencias Políticas y Profesora Asociada de Historia e Instituciones de América Latina de la Facultad de Ciencias Políticas de la Universidad de Bolonia. Además ha escrito y compilado varios libros, entre ellos "Italianid'Argentina. Storie di contadini, industriali e missionari in Argentina” (1983), "Mujeres y Naciones en

Recibido: 5 de junio de 2017 | Aceptado: 28 de junio de 2017 | Publicado: 23 de octubre de 2017

Cita sugerida: Bontempo, M. P. (2017). [Revisión del libro Abril. Un editor italiano en Buenos Aires, de Perón a Videla, por E. Scarzanella]. Trabajos y Comunicaciones, 46, e049. https://doi.org/10.24215/23468971e049 
América Latina. Problemas de inclusión y exclusión” (en coedición con Barbara Potthast, 2001), “Ni gringos ni indios. Inmigración, criminalidad y racismo en Argentina, 1980-1940" (2002), "Fascistas en América del Sur" (2007), "Sin fronteras: encuentros de mujeres y hombres, entre América Latina y Europa (siglos XIX-XX)” (en coedición con Mônica Raisa Schpun, 2008). Algunos de los temas tratados en estas obras emergen como claves interpretativas o contextuales en "Abril...”.

La inmigración, el fascismo en América Latina, las redes familiares, étnicas, religiosas, políticas y transnacionales de migrantes italianos, las empresas familiares y las mujeres periodistas convergen para recrear la historia de la Editorial Abril. El período estudiado abarca toda la vida de la empresa, desde la creación de la editorial, en 1941, hasta la venta de la misma y el exilio de la familia fundadora en 1977 y el cierre definitivo de la firma en los años noventa.

Esta historia incluye también la de las colecciones y publicaciones de la empresa. Entre las más emblemáticas se encuentran: Idilio -romántica-, Misterix -de historietas y aventuras-, Claudia -femenina-, Panorama y Siete días -de actualidad. Algunas de estas revistas significaron una novedad en el mercado editorial, como las fotonovelas de Idilio o el paradigma del fotoperiodismo que propuso Panorama; y otras una modernización respecto a los semanarios de empresas competidoras, como Claudia que "obligó" a otras similares a adecuarse a su modelo. El libro "Abril..." también pone en relieve la pericia y el oficio de aquellas y aquellos que pasaron por las redacciones de algunos de los múltiples emprendimientos de la editorial, como las periodistas Silvia Rudni y Gabriela Courreges, el sociólogo Gino Germani, el artista Héctor Oesterheld, el editor Boris Spivacow, el escritor y guionista Alberto Ongaro, el dibujante Hugo Pratt, los escritores y periodistas Rodolfo Walsh y Tomás Eloy Martínez.

A partir de una variedad de fuentes, desde las propias revistas y libros autobiográficos hasta entrevistas y el Archivo Techint, Scarzanella reconstruye a lo largo de siete capítulos la creación, el desarrollo, la consolidación, la expansión, la transformación en una empresa multinacional -con filiales en Brasil y México que luego se independizaron- y el desmembramiento de la firma.

La autora se centra en la figura de Cesare Civita, artífice de Abril, para recorrer los ciclos de la vida editorial. La investigadora italiana, especializada en historia argentina, analiza cómo el editor de origen judío- italiano, que comenzó una vida en el exilio a partir de las leyes raciales fascistas de 1938, contaba con un "patrimonio de experiencias" (p. 19), producto de su paso en el mundo editorial italiano; un "capital de clase”, constituido por los medios financieros y la vocación empresarial; y un "capital social” compuesto, además de sus vínculos editoriales y familiares, por una red amistad y de identidad con los exiliados judíos italianos. En el relato de Scarzanella, Civita se revela como un emprendedor, con olfato para captar la oportunidad, los gustos y necesidades del público local y con un gran manejo de esas redes de relaciones sintetizadas en el concepto de "capital étnico" (p. 57) para referirse a sus contactos con la comunidad italiana y judía.

La presencia de Civita se torna central para ahondar en la vida de la editorial no sólo en sus comienzos sino también a lo largo del tiempo. De acuerdo a la autora, allí se combinaban las relaciones personales, familiares y de amistad con el profesionalismo, la capacidad artesanal de desempeñar diversas tareas y colaborar en distintas secciones con una organización empresarial “a la americana”, dividida por departamentos y con firmes estándares de trabajo. Un ambiente donde cierta informalidad e intimidad -como las intervenciones de Civita sugiriendo respetuosamente temas o corrigiendo títulos- se traducía en la posibilidad de crear algo nuevo (p. 88). Una editorial donde "no solo se respiraba un clima alegre, relajado y creativo, sino que también reinaba la pasión por el cine, el teatro, la música y la literatura” (p. 86) y que para muchos funcionó como un espacio de aprendizaje antes de formar su propio emprendimiento o de refugio laboral e intelectual para los opositores, muchos de ellos con simpatías socialistas y comunistas, durante el peronismo y luego durante la dictadura de Onganía.

La figura del empresario y editor también fue capital al momento de la conformación de la Asociación Argentina de Editores de Revistas (1948), de la cual Civita llegó a ser su presidente en 1950, del mismo modo que para comprender las relaciones entre esta entidad, las diversas instancias gubernamentales y los sindicatos. Los 
vínculos de Abril -cordiales u hostiles según en período- con el poder y el capital político y económico son desentrañados por Scarzanella con minuciosidad. Especialmente el intento de Civita de controlar todo el proceso productivo, que abarcaba desde la producción de papel hasta la impresión y distribución, mediante la participación -que terminó en un fracaso debido a los vaivenes políticos- en la constitución de Papel Prensa S.A.

La decisión de la investigadora de colocar como hilo conductor del libro a Cesare Civita responde, como demuestra, al lugar que ocupó en la construcción y desarrollo del proyecto editorial Abril. Sin embargo, centrar todo el funcionamiento y ciclo vital de la empresa en su figura obtura otras dimensiones de análisis. Porque si bien se ha advertido sobre la necesidad de prestar atención a la ideología y presencia de los editores, también debe tenerse en cuenta la autonomía de los directores de las diversas publicaciones que componen un grupo editorial. Así, en ocasiones se desdibuja el objeto de estudio y en el desarrollo se pierde el eje de la argumentación. Esta confusión se expresa en una tensión que aparece en la propia elección del título del libro, donde no queda claro si va a tratarse de una historia de la editorial, de la biografía de Civita o de una historia política observada a través del prisma de la empresa. Probablemente, la autora haya querido abarcar todos estos aspectos.

A su vez, la opción de tratar diversos temas y objetos -como el intento de dar cuenta de todas las publicaciones- no permitió la profundización de ninguno. Escasas son las referencias a otras empresas y productos de la competencia, pocas son las preguntas por los públicos lectores, reducidas son las explicaciones de la importancia de las revistas de Abril en y para la cultura argentina a partir de mediados del siglo veinte. De esta manera, el resultado es un texto que tiende a describir más que a explicar.

Es indudable que la editorial Abril y sus productos constituyen un punto de referencia ineludible para quienes se encuentran interesados en la segunda mitad del siglo veinte. En este sentido, el texto de Eugenia Scarzanella constituye un mapa con información rica sobre la empresa editorial y las estrategia comerciales que implementó y tejió; una cartografía de los periodistas, sus vínculos y círculos de amistad; una guía sobre los temas que preocupaban a los diversos públicos o que eran instalados por las revistas; un texto de indicios sobre las experiencias en el campo de la lectura. De esta manera, el gran aporte de "Abril..." es brindar pistas y probablemente abrir futuras líneas de investigación vinculadas con el campo de la cultura. 